\title{
EXPERIMENTAL INVESTIGATION OF THE IMPACT OF FLIGHT SPEED ON DRAG FORCE IN THE AUTOGYRO MODEL
}

\author{
Zbigniew Czyż', Paweł Magryta' ${ }^{1}$, Marcin Szlachetka ${ }^{2}$
}

1 Department of Thermodynamics, Fluid Mechanics and Aviation Propulsion Systems, Faculty of Mechanical Engineering, Lublin University of Technology, Nadbystrzycka 36, 20-618 Lublin, Poland, e-mail: z.czyz@pollub. pl; p.magryta@pollub.pl

2 Department of Mechanics and Mechanical Engineering, Pope John Paul II State School of Higher Education in Biala Podlaska, Sidorska 95/97, 21-500 Biała Podlaska, Poland, e-mail: m.szlachetka@dydaktyka.pswbp.pl

Received: 2015.04 .07 Accepted: 2015.05.08 Published: 2015.06.01

\begin{abstract}
The paper presents the experimental investigation of the impact of velocity on drag force in the autogyro model. One of the methods which simulate motion of the flying object consists of using a wind tunnel. In this case, test object is stationary and the motion of air is forced by e.g. a special fan. The costs related with renting and the wind tunnel service are still very high. In this paper, the motion of the autogyro with respect to the air, was produced by fixing this model with scale to measure the drag force on the passenger car roof. The position of the object relative to the vehicle was checked on the basis of numerical analysis of the airflow around this vehicle. Based on the investigations, the field of velocity and pressure, and air flow formed around the contour of the vehicle which have been chosen, were determined. In addition, the drag force characteristic was determined as a function of velocity and it was compared with the values from the numerical analysis. This research is a form of verifying opportunities for this type of research on vehicles. The conclusions derived from the analysis of the results will be used in the future to carry out further research.
\end{abstract}

Keywords: autogyro, aerodynamics, CFD, wind tunnel, airflow.

\section{INTRODUCTION}

Aerodynamic experimental investigation allow to obtain aerodynamic characteristics, to verify and investigate the stability, and to verify hazardous flight conditions of aircraft or other research objects. One way to simulate the motion of flying objects is the use of the wind tunnel. In this case, the test object is stationary relative to the ground and the air movement is forced by a special fan. This allows us to perform a lot more research than in real flight conditions. Of course, in addition to the wind tunnel, advanced measuring equipment that measure both the loads acting on the test object and visualization of flow around it are often required. Research and measurement in wind tunnels associated with high costs of rent and service. In addition, the size of the research object is limited by the size of the wind tunnel test section. Often, the object must be scaled in order to ensure the correct proportions in relation to the measuring chamber [1].

The dimensions of the tunnel are the barrier in the case studies, which should be reflected in real scale. If the model test results are to be referenced to the real objects certain dependencies, which are called the similarity laws must be complied. They take into account the geometrical, kinematic and dynamic criteria. Geometric similarity is a consequence of the need to introduce, the so-called, linear scale. Linear scale is defined as the ratio of the linear dimension of the model corresponding to the linear dimension of the real object. Geometric similarity is relatively easy to obtain. But in the case of kinematic similarity, kinematics of individual components in- 
cluding the mapping of all the twists and fluctuations in the position of objects relative to the airflow should also be similar. Dynamic similarity is much harder to keep. This type of similarity is observed when the forces acting on the real object and the model are consistent with the terms of similarities. For this purpose, it is necessary to keep the number of criterion, among which we can find the Mach number, the coefficient of forward velocity, Froude number, Strouhal number or Reynolds and Locke number [2].

The more we reduce the object size, the number of criterial and transform results on a real object are more difficult to keep. Department of Thermodynamics, Fluid Mechanics and Aviation Propulsion Systems at Lublin University of Technology is equipped with a GUNT HM 170 wind tunnel which has the cross-section of the test chamber $292 \times 292 \mathrm{~mm}$ respectively. In order to examine EM-11 Orka plane with a span of $13.5 \mathrm{~m}$ in this tunnel, it should be reduced at least 67 times. If we do so, the Reynolds number, which is the ratio of the aerodynamic forces of inertia to air viscosity should increase the flow rate by the same times. Even in the case of the minimum velocity for the aircraft, which is $90 \mathrm{~km} / \mathrm{h}$, the velocity in wind tunnel should be equal to $6030 \mathrm{~km} / \mathrm{h}$. Only in this case, this number does not meet the criterion (with the same working medium). It is also not clear if the fact that the phenomena occurring at the actual flow around the aircraft and the model will be the same. In addition, such a high flow velocity are not possible to achieve using this wind tunnel and we will be not able to meet different criterion numbers. Recognizing the need to study larger objects, it was decided to verify the alternative method, in which the movement of the autogyro (research object) to air was produced by fixing the autogyro with scales to measure the drag force on the car roof. So it is a moving car that forces the air flow around the test object. This method, depending on the used scale makes possible to test individual components provides a measure of the aerodynamic forces and moments.

The results of resistance force obtained from the experiment were compared to the results obtained by numerical calculations. Numerically obtained velocity field of pressure and air flow formed around the contours of the vehicles allowed accurately assess the measurement in conditions that were shown.

\section{RESEARCH OBJECT AND METHODOLOGY}

The object of the research was autogyro model, called Gyro - One, which is shown in Figure 1. This is an unmanned RC aircraft, which is propelled using $1000 \mathrm{~W}$ electric engine with a maximum take-off weight of about $4 \mathrm{~kg}$. Autogyro is over $1.050 \mathrm{~mm}$ in length and $510 \mathrm{~mm}$ in height. Main rotor diameter is $1800 \mathrm{~mm}$. More details about the object are added in a different paper [3].

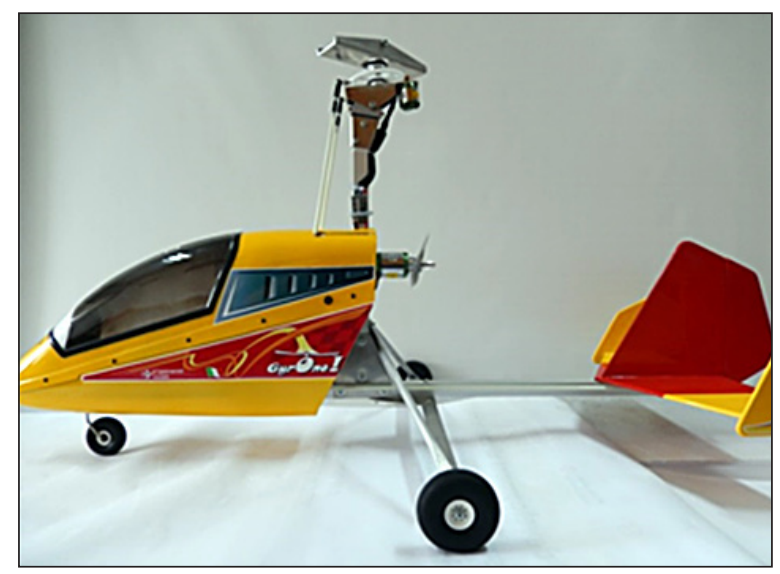

Fig. 1. Research object Gyro - One

Autogyro is mounted on the balance scale equipped with a strain gauge for measuring an additional resistance force (Fig. 2). Autogyro is fixed to the mast (1) mounted on a linear bearing (6). Under the pressure of the air flow it produces the tension on the strain gauge (2) by a rod (7). The signal from the strain gauge is processed by measuring cards and read using a program developed in LabVIEW software.

The whole structure was mounted on a vehicle with a luggage rack. For the experiment, Opel Vectra sedan B was used. Autogyro was po-

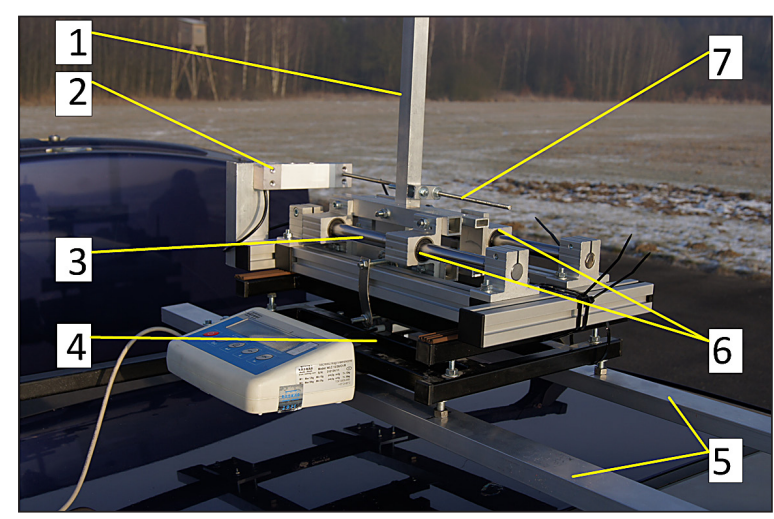

Fig. 2. View of balance scale, 1. mast, 2. strain gauge to measure the power of drag force, 3. rails, 4. platform for scales to measure lift, 5. stringers, 6. linear bearings 
sitioned at a height of about $670 \mathrm{~mm}$ measured from the surface of the roof. Despite the completed tests including the main rotor rotation, this paper presents only the results of the research object without the main rotor blades.

Tests were carried out in a qualified Technician Improvement Centre of Driving - Moto Park in Ulez. This place is adopted from the old military airport. There is a main starting lane with a length of $1500 \mathrm{~m}$ and a width of $30 \mathrm{~m}$. It allowed for carrying out the tests in which the influence of the ground is smaller than on random street. The decision to undertake research on a rented former military airport has also been taken for security reasons.

\section{NUMERICAL METHOD AND BOUNDARY CONDITIONS}

Experimental studies have been extended by a simulate flow around the vehicle and autogyro. As the main object of interest is the autogyro model, it was decided that for this object the calculations will be carried out in 3D and in the case of a vehicle a $2 \mathrm{D}$ simulation will be made, to find out the field of flow around the vehicle in the longitudinal plane passing through the center of the car, which may help in the analysis of results. For this purpose, the contour of the vehicle (Fig. 4) was traced in Catia v5 and then imported to Design Modeler (Ansys Fluent). After completing the grid, the computing model was loaded into the solver (Ansys Fluent). Table 1 shows the general settings for the numerical analysis of flow around the vehicle geometry.

Table 1. General settings of numerical analysis for the airflow around the vehicle

\begin{tabular}{|c|c|c|c|}
\hline Basic & Type & \multicolumn{2}{|l|}{ Pressure-based } \\
\hline parameter & Time & \multicolumn{2}{|l|}{ Steady } \\
\hline Models & $\begin{array}{l}\text { Viscous } \\
\text { model }\end{array}$ & \multicolumn{2}{|c|}{ k-omega (2-eqn) SST } \\
\hline \multirow{3}{*}{ Materials } & Fluid & \multicolumn{2}{|l|}{ Air } \\
\hline & Density & \multicolumn{2}{|c|}{ Incompressible-ideal-gas } \\
\hline & Viscosity & Constant & $1.7894 \mathrm{e}-05$ \\
\hline \multirow{6}{*}{$\begin{array}{l}\text { Boundary } \\
\text { conditions }\end{array}$} & \multirow{3}{*}{ Inlet } & Velocity & $72[\mathrm{~km} / \mathrm{h}]$ \\
\hline & & \begin{tabular}{|l} 
Turbulent \\
intensity [\%]
\end{tabular} & 10 \\
\hline & & $\begin{array}{l}\text { Hydraulic } \\
\text { diameter [m] }\end{array}$ & 14 \\
\hline & \multirow{3}{*}{ Outlet } & Pressure-outlet & $\begin{array}{c}\text { gauge } \\
\text { pressure } 0 \mathrm{~Pa}\end{array}$ \\
\hline & & $\begin{array}{l}\text { Turbulent } \\
\text { intensity [\%] }\end{array}$ & 10 \\
\hline & & $\begin{array}{l}\text { Hydraulic } \\
\text { diameter [m] }\end{array}$ & 14 \\
\hline
\end{tabular}

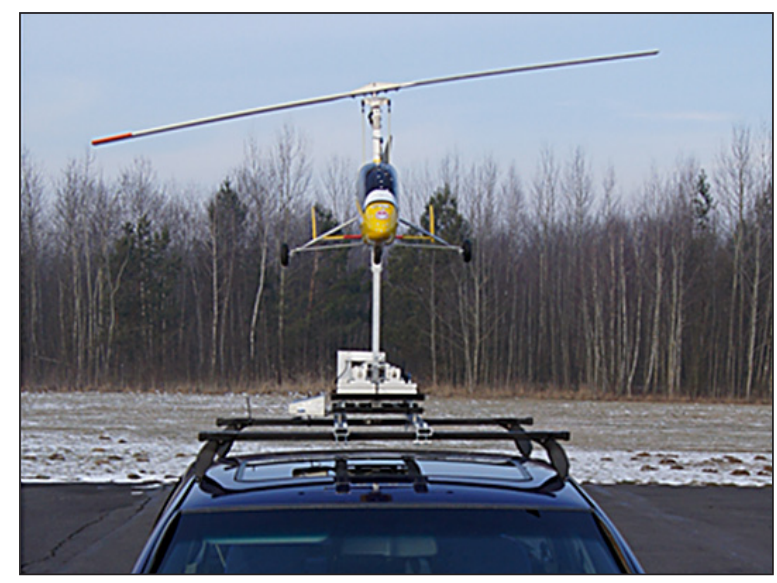

Fig. 3. View autogyro placed on a vehicle

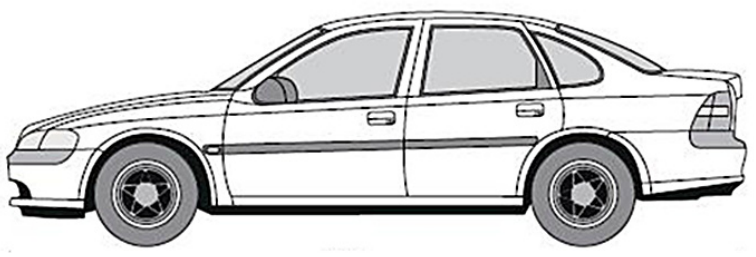

Fig. 4. The two-dimensional draft of a vehicle Opel Vectra B - side view [4]

Autogyro 3D model was done in CATIA V5 software. Figure 5 shows the views of a solid model of the autogyro. The model is without head rotor, blades and an engine. In addition, aircraft interior components, such as accumulators, receiver, cabling were not included in the modeling. It is justified by the type of performed analysis, which is an external flow around the geometry of the tested object. Further simplification involved small, non-significant changes like fasteners -

Table 2. General settings of numerical analysis for the airflow around the autogyro geometry

\begin{tabular}{|c|c|c|c|}
\hline \multirow{2}{*}{\begin{tabular}{|l} 
Basic \\
parameters
\end{tabular}} & Type & \multicolumn{2}{|l|}{ Pressure-based } \\
\hline & Time & \multicolumn{2}{|l|}{ Steady } \\
\hline Models & $\begin{array}{l}\text { Viscous } \\
\text { model }\end{array}$ & \multicolumn{2}{|c|}{ k-omega (2-eqn) SST } \\
\hline \multirow{3}{*}{ Materials } & Fluid & \multicolumn{2}{|l|}{ Air } \\
\hline & Density & \multicolumn{2}{|c|}{ Incompressible-ideal-gas } \\
\hline & Viscosity & Constant & $1.7894 \mathrm{e}-05$ \\
\hline \multirow{6}{*}{$\begin{array}{l}\text { Boundary } \\
\text { conditions }\end{array}$} & \multirow{3}{*}{ Inlet } & Velocity & $0-90[\mathrm{~km} / \mathrm{h}]$ \\
\hline & & \begin{tabular}{|l} 
Turbulent \\
intensity [\%]
\end{tabular} & 1 \\
\hline & & $\begin{array}{l}\text { Turbulent length } \\
\text { scale }[\mathrm{m}]\end{array}$ & 0.28 \\
\hline & \multirow{3}{*}{ Outlet } & Pressure-outlet & $\begin{array}{c}\text { gauge } \\
\text { pressure } 0 \mathrm{~Pa}\end{array}$ \\
\hline & & $\begin{array}{l}\text { Turbulent } \\
\text { intensity [\%] }\end{array}$ & 1 \\
\hline & & $\begin{array}{l}\text { Turbulent length } \\
\text { scale }[\mathrm{m}]\end{array}$ & 0.28 \\
\hline
\end{tabular}




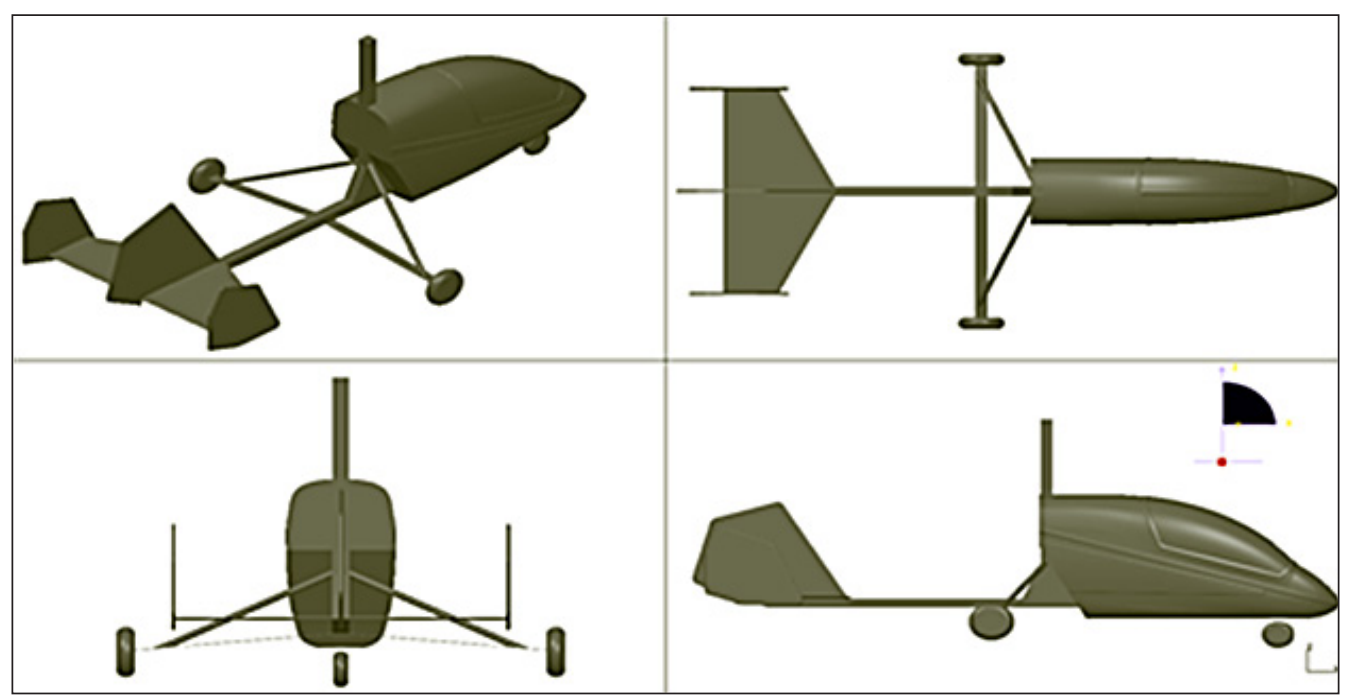

Fig. 5. Geometric model of the autogyro prepared for the CFD analysis

bolts, nuts, and holes. Table 2 shows the general settings for the numerical analysis of flow around the autogyro geometry.

\section{RESULTS AND DISCUSSIONS}

Figure 6 shows the drag force as a function of velocity of the moving vehicle. Results recorded from several testes were approximated with a second-degree polynomial line.

The drag force from experimental research as a function of the velocity of vehicle were compared with the results of numerical calculations. It turns out that the drag force of the numerical calculations account for about $50 \%$ of the experimental results.

In order to explain such a large differences it was decided to investigate the velocity and the pressure field around the used vehicle. Figure 8 shows the pressure field around the vehicle. We can observe that at the transition between the surface of the glass and the roof area, the pressure is about $-0.6713 \mathrm{kPa}$. Static pressure drop causes an increase in the flow rate as it is shown in Figure 9. Undisturbed air stream velocity is $20 \mathrm{~m} / \mathrm{s}$ (the boundary condition of numerical analysis), and increases nearly doubled in the largest vacuum.

In order to determine the velocity field around the autogyro, additional figure 10 was shown, in which autogyro model was applied into the velocity field map.

It can be seen that the velocity field, where the autogyro is mounted is not uniform. In the lower part of the object of the velocity is about $29 \mathrm{~m} / \mathrm{s}$ while at the top it decreases to about $25 \mathrm{~m} / \mathrm{s}$. For simplicity, we can assume that the average speed acting on the model is $27 \mathrm{~m} / \mathrm{s}$. If we consider this value of the velocity in the calculation of the drag

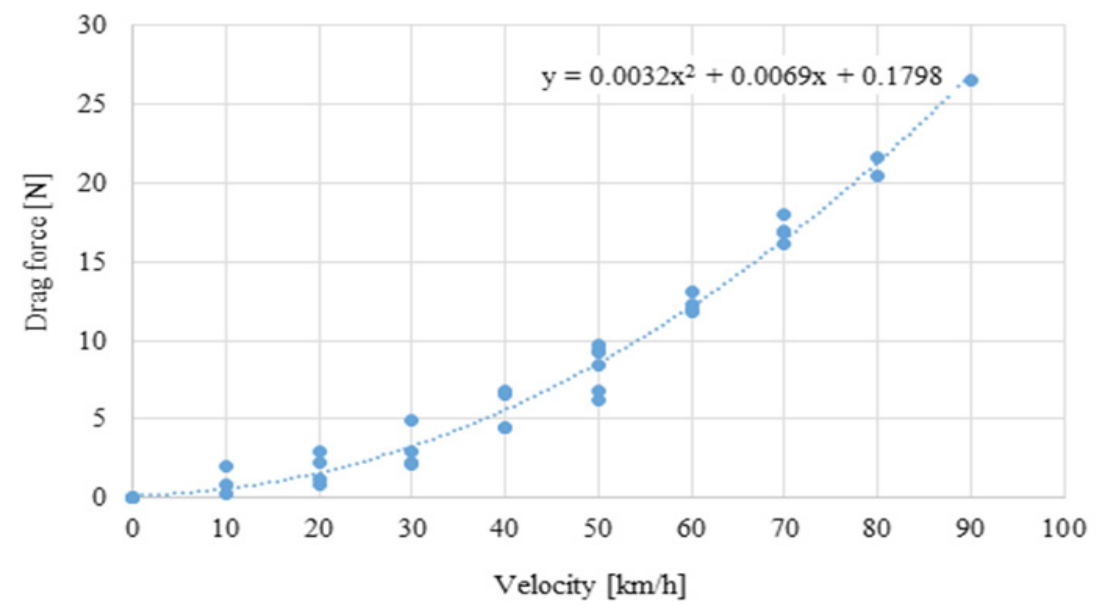

Fig. 6. The drag force as a function of velocity obtained from experimental studies 


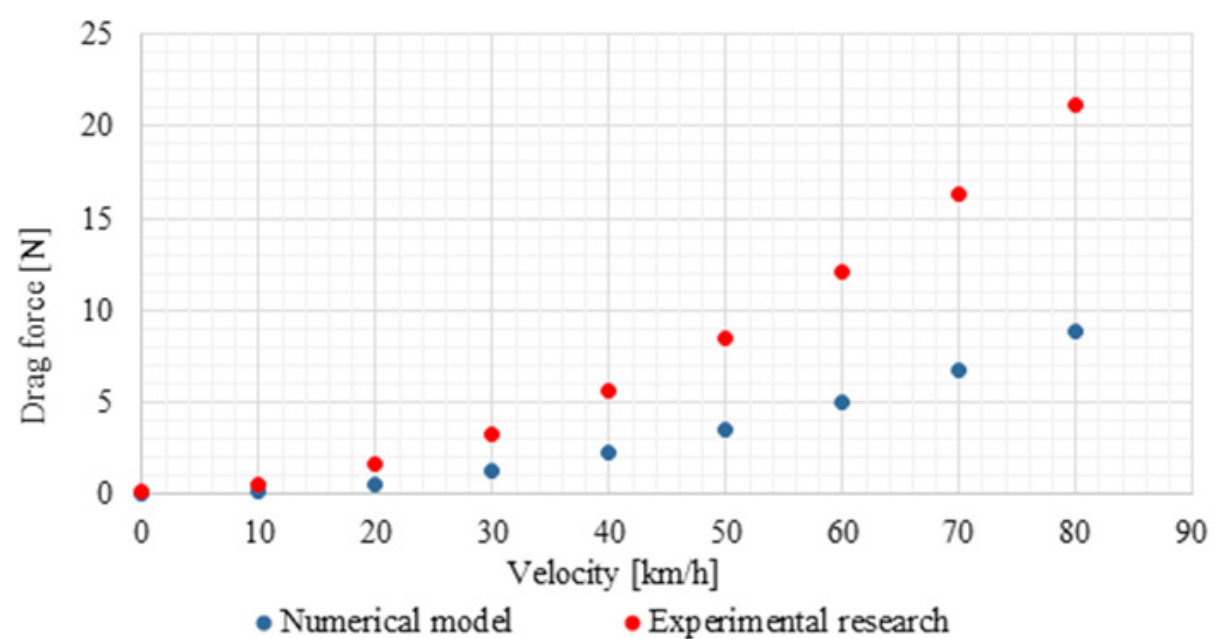

Fig. 7. Comparison of the drag forces as a function of the vehicle velocity for the calculation model and experiment

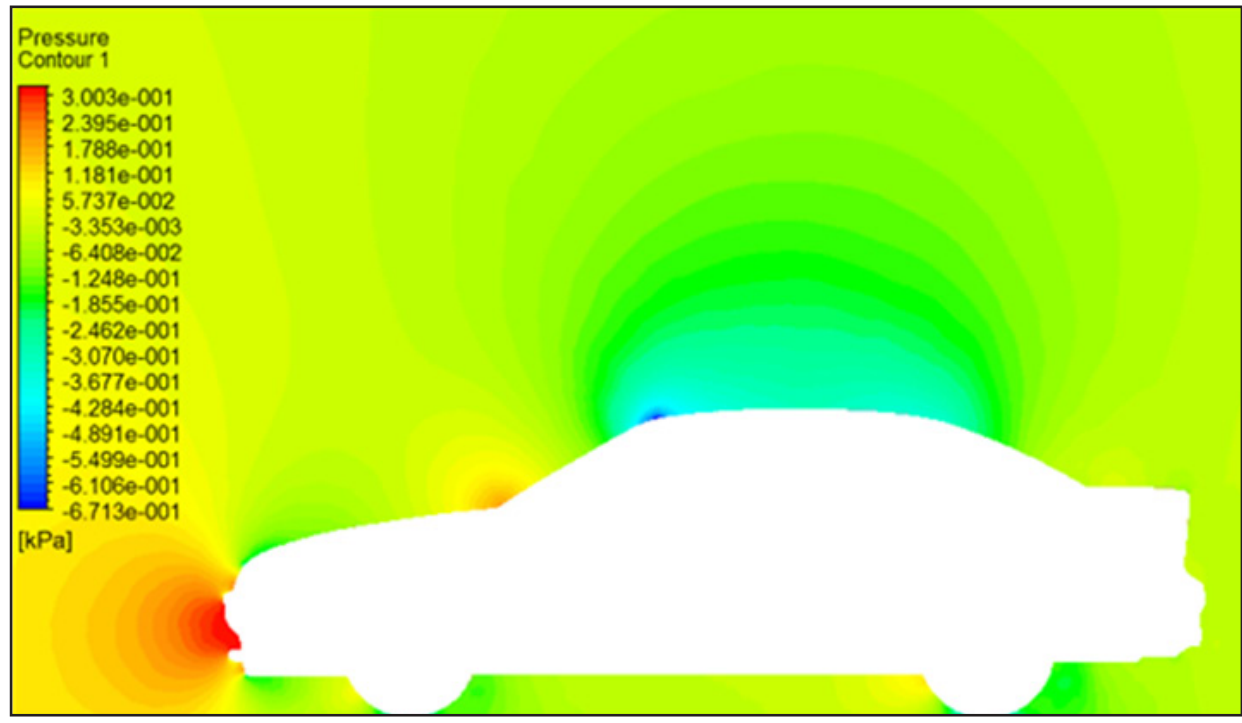

Fig. 8. Pressure field around the vehicle

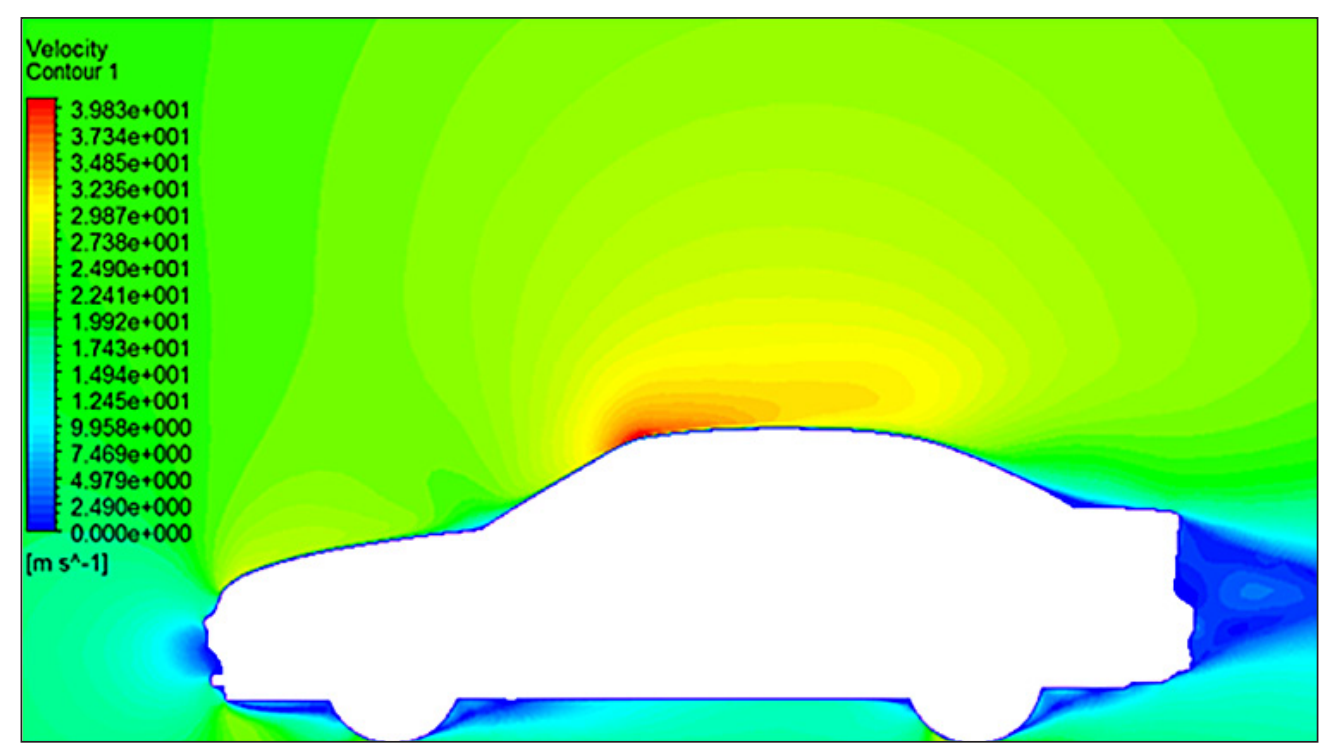

Fig. 9. Velocity field around the vehicle 


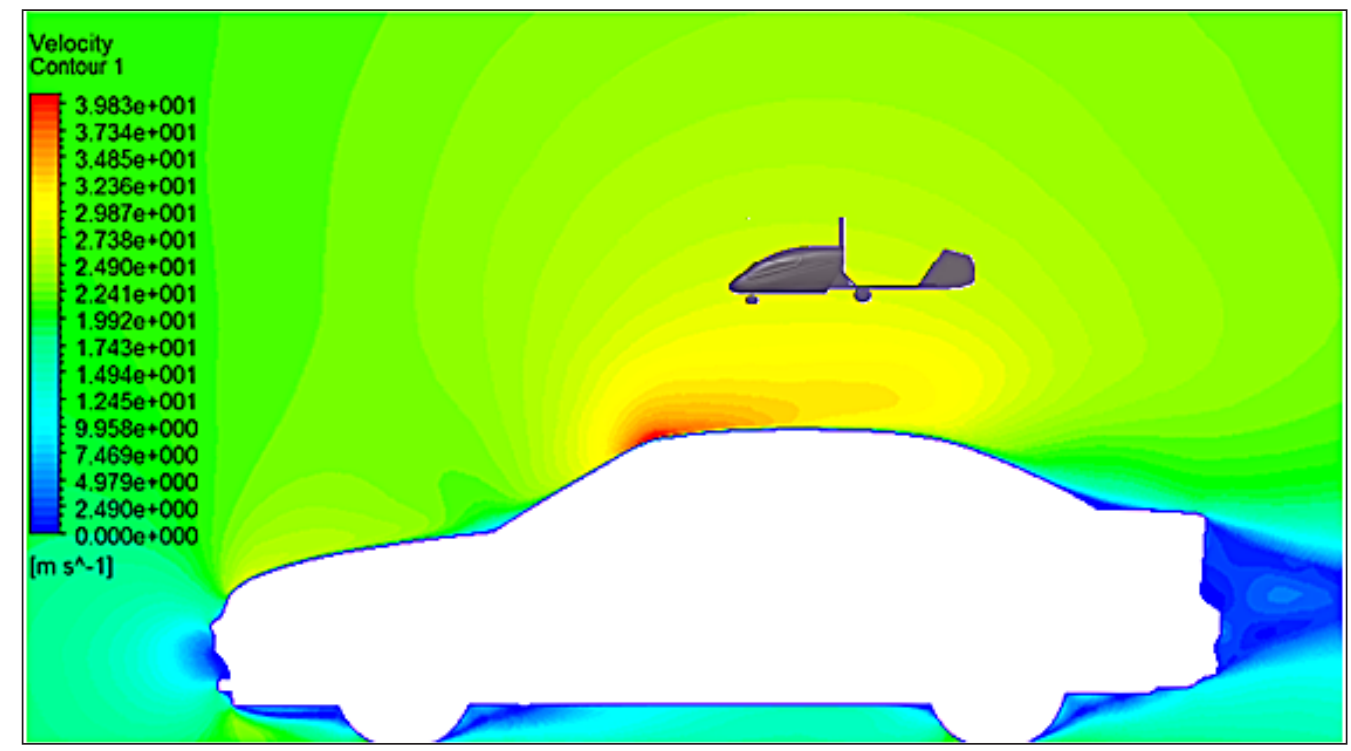

Fig. 10. Velocity field around the vehicle with the autogyro

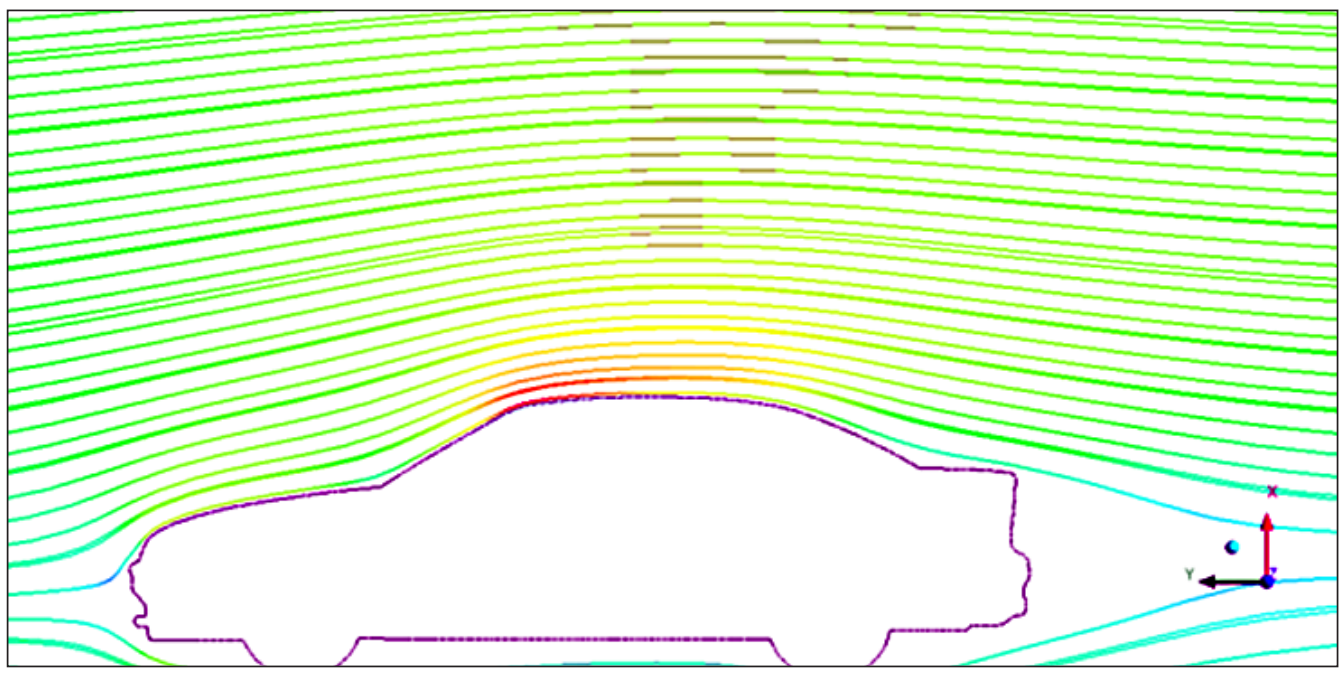

Fig. 11. Air streams around the vehicle

force (1) it turns out, that the component $v^{2}$ in numerical computation is equal to $400 \mathrm{~m}^{2} / \mathrm{s}^{2}$ (for 20 $\mathrm{m} / \mathrm{s}$ ) which corresponds to $54.9 \%$ in relation to the actual test $\left(729 \mathrm{~m}^{2} / \mathrm{s}^{2}\right.$ for the $\left.27 \mathrm{~m} / \mathrm{s}\right)$.

$$
P_{x}=0.5 \cdot C_{x} \cdot \rho \cdot A \cdot v^{2}
$$

Except for the velocity and pressure field we should pay attention also to the shape of the air streams which surround the vehicle. It turns out that even the addition of significant changes in velocity and pressure in the cross-sectional shape, the air flow is also affected (there is a deviation of flow) and in a relatively large distance from the roof surface. Deviation of the velocity vector indeed affect the aerodynamic force component.

\section{CONCLUSIONS}

Confrontation of experimental methods for measuring aerodynamic forces with the numerical method allows for the verification of the test results. As it is shown in the article, the alternative way of research is less expensive than wind tunnel tests, however, it requires consideration of a number of external factors affecting the results. Computational model almost always differs from real experiments. It has idealized conditions that it makes easy to repeat the steady boundary or initial conditions. In case of real research, we often receive a scatter of results, from which we draw a trend line. Not focusing on the drawbacks of numerical analysis, we can conclude that the disparity of experimental and 
CFD simulation results is due to a big impact of air velocity around the vehicle. The geometric model used in the numerical analyzes was slightly different from the object used in the experiment. Some of the elements that produce additional drag force (mast, components mounted on slides of linear bearings, rotor head) were not properly covered.

Research allows to estimate the value of aerodynamic force components. A more detailed analysis with the additional use of CFD allows for the correct interpretation of the results. Further research should take into account all the abovedescribed issues with particular emphasis on the selection of a vehicle and platform on which the test object will be attached.

\section{REFERENCES}

1. Krysztofiak G.: Tunelowe badania wpływu usterzenia motylkowego na charakterystyki aerodynamiczne modelu kadłuba wiatrakowca. Modelowanie inżynierskie 42, 2011, 227-232.

2. Krysztofiak G.: Kryteria podobieństwa aerodynamicznego $w$ tunelowych badaniach modeli wirników wiropłatowych statków powietrznych. Modelowanie inżynierskie 42, 2011, 217-226.

3. Czyż Z., Wendeker M., Raczyński R.: Koncepcja hybrydowego statku powietrznego $\mathrm{z}$ napędem wielowirnikowym. Logistyka 6, 2014, 2936-2945.

4. http://opelastra24.eu.interiowo.pl/modele/opel_ vectra_b_wymiary.html 